\title{
O impacto dos gastos do governo federal no desmatamento no Estado do Pará
}

Rodolfo Coelho Prates Professor do IBPEX e da Universidade Positivo

Maurício Serra

Professor do Departamento de Economia da Universidade Federal do Paraná

\section{Palauras-chaves \\ Amazônia, desmatamento, gasto público, dados em painel.}

Classificação JEL H5, Q23, R58.

\footnotetext{
Key words

Amazon, Pará State, deforestation, federal spending, data panel.

JEL Classification H5, Q23,
} $\mathrm{R} 58$.

\section{Resumo}

O desmatamento da floresta amazônica é um dos principais problemas ambientais enfrentados pelo Brasil. A literatura aponta inúmeras causas ou fatores para o desmatamento, e muitos deles são, direta ou indiretamente, derivados de gastos realizados pelo governo federal. Nesse sentido, o objetivo deste artigo é analisar empiricamente, através de um modelo econométrico de dados em painel, como os gastos do governo influenciam o desmatamento na região amazônica ou mesmo o atenuam. O Pará é utilizado como estudo de caso por apresentar o maior grau de desmatamento dentre todos os estados amazônicos.

\section{Abstract}

The deforestation of the Amazon forest is one of the most important environmental problems faced by the Brazilian government.

The economic literature points to numerous factors responsible for deforestation, and many of these are, directly or indirectly, derived from federal spending.

This article analyzes, through a panel data econometric model, how federal spending can influence, or mitigate, Amazonian deforestation. The state of Pará is used as a case study, as it presents the highest degree of deforestation among all Amazonian states. 


\section{1_Introdução}

O desmatamento da floresta amazônica brasileira consiste em um dos principais problemas ambientais enfrentados pelo Brasil atualmente. Os dados divulgados pelo Instituto Nacional de Pesquisas Espaciais (Inpe) sobre a retirada da cobertura florestal na região atestam que, nos últimos dez anos, a média foi superior aos $18 \mathrm{mil} \mathrm{km} \mathrm{km}^{2}$. A esse ritmo, a cada cinco anos, é desmatada uma área equivalente a todo o Estado de Santa Catarina. Os dados também revelam que a área já desmatada na Amazônia até o presente momento é superior a área dos três Estados que compõem a região Sul do País (Inpe, 2008).

As causas do desmatamento já estão amplamente estudadas e incluem diversos fatores, como o preço dos produtos agropecuários, as condições de acesso, os gastos do governo, o nível de renda e a presença da população, por exemplo, cabendo aqui a ressalva de que alguns fatores estão mais presentes e atuantes em alguns Estados que em outros.

Muitos dos fatores causadores do desmatamento relacionados na literatura, direta ou indiretamente, são derivados de políticas realizadas pelo governo federal, como crédito rural ou ampliação e melhoria das rodovias, por exemplo. O governo pode estimular, por meio das políticas públicas, o desmatamento mediante a liberação de recursos que indiretamente afetam atividades que necessitam do solo, a exemplo da agropecuária. Gastos do governo nesse aspecto estão sob a responsabilidade do Ministério da Agricultura. Outros ministérios, como o de Transporte, executam gastos para ampliar e melhorar as condições logísticas, que, por sua vez, impactam sobre o desmatamento.

Por outro lado, existem políticas públicas federais de controle e combate ao desmatamento. O ministério competente, nesse caso, é o do Meio Ambiente, que, por meio de órgãos como o Instituto Brasileiro do Meio Ambiente e dos Recursos Naturais Renováveis (Ibama), visa conservar e preservar o meio ambiente em seu estado natural. Nesse aspecto, surge uma questão importante que sustenta a hipótese central deste trabalho: para a mesma região, o governo realiza gastos em políticas que têm funções opostas, e, por isso, se anulam. Em suma, o governo realiza gastos que afetam o desmatamento em determinada região e, ao mesmo tempo, efetua novos gastos para mitigar o desmatamento.

Diante desse contexto, o objetivo deste artigo é compreender empiricamente, por meio de um modelo econométrico de dados em painel entre 2002 e 2004, co- 
mo os gastos do governo influenciam o desmatamento na região amazônica ou o atenuam. O Pará é utilizado como estudo de caso por apresentar o maior grau de desmatamento entre todos os Estados amazônicos (Inpe, 2008). Em função do objetivo, o presente artigo está estruturado, além desta introdução, em quatro seções. A segunda seção apresenta um breve panorama da literatura acerca do desmatamento na Amazônia brasileira. Na terceira seção, o objetivo é explicitar não só a seleção das variáveis explicativas, como também os procedimentos de estimação dos parâmetros para o modelo econométrico adotado. Os resultados gerados pelo modelo econométrico são apresentados e discutidos na quarta seção. Por último, na quinta seção, as considerações finais são tecidas.

\section{2_Revisão bibliográfica}

Esta seção apresenta um breve panorama sobre a discussão das causas do desmatamento, particularmente na Amazônia brasileira. Pelo fato de o objetivo deste artigo tratar de um modelo econométrico para mensurar os fatores geradores do desmatamento, os trabalhos aqui mencionados serão preferencialmente os que também adotaram algum procedimento econométrico, sem perder de vis- ta os grandes vetores que impulsionam o desmatamento na região amazônica.

A literatura sobre o desmatamento mostra claramente que há inúmeros fatores responsáveis pelo desmatamento e também são muitos os estudos que buscam relacionar o desmatamento com as suas causas. Existe certo consenso na literatura específica sobre o desmatamento na região amazônica de que alguns fatores são, de fato, relevantes, tais como a abertura e a pavimentação de estradas ou outras obras de infraestrutura (Laurance, Albernaz, Fearnside, Vasconcellos e Ferreira, 2004; Soares Filho, Nepstad e Curran, 2005; Weinhold e Reis, 1999), o avanço da pecuária (Margulis, 2003) e da soja (Brandão, Rezende e Marques, 2005; Fearnside e Graça, 2006).

Além desses fatores, a população também é uma variável de grande representatividade para explicar a causa do desmatamento (Cropper, Griffiths e Mani, 1996; Andersen e Reis, 1997; Tanaka e Nishii, 1997; Cullas e Dutta, 2002; Perz, Aramburú e Bremner, 2005; Barreto, Souza Júnior, Noguerón, Anderson e Salomão, 2005). No entanto, existem visões distintas de sua relação com o desmatamento. De fato, Tanaka e Nishii (1997) afirmam que a variável população incorpora implicitamente outras variáveis, tornando-as desnecessárias. Além disso, ela é de fácil mensuração, o 
que facilita os trabalhos de natureza empírica. Por outro lado, Hogan (2001) ressalta que considerar a população como única variável explicativa do desmatamento não capta as verdadeiras razões para o desmatamento, a exemplo das inúmeras ações econômicas que sucedem a floresta.

A variável rodovia, mensurada pelo custo de transporte ou da extensão da malha rodoviária ou ainda pela distância de um determinado ponto a um centro de consumo, abastecimento ou exportação, também se mostrou bastante presente nos trabalhos empíricos sobre o desmatamento (Cropper, Griffiths e Mani, 1996; Pfaff, 1999; Weinhold e Reis, 1999 e 2003). Arima, Walker, Perz e Caldas (2005) utilizaram a combinação entre a teoria do comportamento do consumidor e o sistema de informações geográficas para analisar as decisões espaciais dos agentes econômicos, e a conclusão foi de que o avanço do desmatamento se deu como consequência das rodovias. Resultados semelhantes são encontrados no trabalho de Pfaff et al. (2007), que analisaram o impacto da ampliação das rodovias sobre o desmatamento na Amazônia e concluíram que o aumento das rodovias na região, pavimentadas ou não, contribuiu para o aumento do desmatamento. Weinhold e Reis (1999) analisaram a conexão entre o crescimento populacional e o cres- cimento da infraestrutura em 295 municípios da Amazônia, entre 1975 e 1985. O diferencial do trabalho foi ter incorporado a infraestrutura como variável endógena no modelo, ao contrário de outros trabalhos, que apontaram a sua exogeneidade, ou seja, é o crescimento da infraestrutura que impulsiona o aumento populacional, que, por sua vez, expande o desmatamento.

No entanto, a maior parte das ações que visam à construção, ampliação e manutenção das rodovias é de responsabilidade dos governos, e a esse respeito ainda carece de trabalhos empíricos que mensurem os gastos do governo relacionados a essa finalidade com o desmatamento nos municípios onde elas passam.

Uma importante pesquisa é a de Andersen e Reis (1997), os quais estimaram um modelo de desmatamento baseado na demanda por terra agrícola visando avaliar, entre 1970 e 1985, os diferentes instrumentos de política de desenvolvimento. O modelo levou em consideração a população, o nível de urbanização do município, o ritmo de crescimento do mercado local, o preço da terra e as ações governamentais. O trabalho aponta que o crédito agrícola implica resultados econômicos positivos após a derrubada da floresta; já os projetos de construção de rodovias podem não trazer os resultados econômicos esperados. 
O desmatamento em oito Estados amazônicos, entre 1980 e 1998, associado à expansão da agricultura e da pecuária, foi analisado por Ferraz (2001), que mostrou que a expansão agrícola se relaciona positivamente com a presença de estradas, com o crédito agrícola e com o preço da terra, ao passo que a pecuária se relaciona positivamente com as rodovias e negativamente com o preço do gado.

Pfaff (1996) analisou os determinantes do desmatamento da Amazônia brasileira, no período de 1978 a 1988. O modelo econométrico adotado consistiu em determinar uma equação representativa dos vários fatores possíveis causadores do desmatamento, sendo seu pressuposto básico o fato de que a terra é alocada entre usos alternativos para maximizar o retorno. Os resultados obtidos estão em harmonia com a teoria e com os demais estudos empíricos: o aumento da malha rodoviária tem impacto positivo sobre o desmatamento, os projetos governamentais de desenvolvimento também aceleram o desmatamento, as áreas distantes dos mercados são menos susceptíveis ao desmatamento e os solos mais férteis constituem atributos favoráveis ao desmatamento. Pfaff ressaltou não ter encontrado relação entre a dimensão populacional e o desmatamento, quando essa variável é analisada conjuntamente com as demais.
As razões do crescimento da agricultura e da pecuária na Amazônia, no período de 1980 a 1995, foram analisadas por Ferraz (2000) por meio de modelos de regressão múltipla, relacionando as variáveis dependentes "conversão de florestas em áreas agrícolas e em áreas para a pecuária" com o valor da produção, custo de insumos (preço da terra e salário rural), extensão de rodovias pavimentadas e não pavimentadas e crédito agrícola.

Torna-se importante sublinhar que o governo federal, especificamente no contexto agropecuário, tem diretamente dois grandes mecanismos de estímulo a essa atividade: crédito agrícola e gastos em agricultura. Todos os outros mecanismos, como os gastos em questões agrárias e no sistema de transporte, só o fazem indiretamente.

As despesas não financeiras do gasto público federal foram analisadas por Piancastelli e Pereira (1996), que constataram que o gasto do Ministério do Meio Ambiente nos anos de 1994 e 1995 foi, respectivamente, de 0,01 e 0,03\% do PIB. Apesar do aumento, o valor gasto foi bem abaixo do de outros ministérios.

Young (2005) constatou que a conservação da biodiversidade no Brasil dependia fortemente do setor público, particularmente do federal, principalmente via redistribuição de impostos, compensações 
ambientais, cobrança pelo uso da água e o pagamento de "royalties" de eletricidade, petróleo e gás natural. No entanto, as políticas públicas ainda carecem de um objetivo comum para que suas ações sejam eficientes. Além do mais, as crises fiscais comprometeram fundamentalmente os gastos em preservação ambiental.

Os gastos públicos federais para a preservação do meio ambiente nos anos 1990 variaram entre 0,6 e 1,0\% do PIB, e, nos últimos anos daquela década, houve ligeira queda dos valores gastos. Houve também inúmeros acordos internacionais de captação de recursos para a preservação ambiental, principalmente para a Amazônia (Young e Roncisvalle, 2002).

O levantamento macroambiental do Brasil foi elaborado pelo IBGE (2004), e o documento mostra claramente que a parcela de gastos públicos totais destinados à proteção do meio ambiente nunca ultrapassou o valor de $1 \%$ dos gastos totais, sendo as esferas estadual e municipal as que proporcionalmente mais gastam com o meio ambiente. Especificamente em 2000, o levantamento ressaltou que a participação relativa no total das despesas públicas nas três esferas governamentais era as seguintes: $0,42 \%$ na federal, $0,57 \%$ na municipal e $0,82 \%$ na estadual. O levantamento também apontou que a maior concen- tração dos gastos estava na região Norte do País.

É possível observar, nesta breve revisão de literatura, que muitas das causas do desmatamento estão, direta ou indiretamente, relacionadas com as políticas adotadas pelo governo federal. Nesse sentido, o presente artigo visa esclarecer alguns pontos que não foram cobertos por trabalhos anteriores, a saber: o entendimento de parte das diferentes políticas adotadas pelo governo federal e sua relação com o desmatamento na Amazônia Legal.

\section{Referencial analítico e metodológico}

A Figura 1 mostra a relação geral entre as grandes divisões institucionais da sociedade e o processo de desmatamento. Particularmente, ela permite compreender, em uma escala mais ampla, a interconexão dos diversos tipos de fator que afetam diretamente ou indiretamente o desmatamento. $\mathrm{O}$ passo inicial é identificar o agente responsável pelo desmatamento e sua importância relativa no processo, a exemplo dos produtores agropecuários, já que eles são os agentes diretos do desmatamento. Os parâmetros de decisão dos agentes são constituídos por elementos que afetam diretamente a decisão dos agentes 
do desmatamento, como, por exemplo, o preço dos bens agrícolas, o volume de crédito disponibilizado ao setor agropecuário e os custos de produção. E, finalmente, as variáveis de nível macro e os instrumentos políticos são dados pelas condições demográficas, pelas políticas governamentais, pelos preços mundiais das commodities, pelas tendências macroeconômicas e pela tecnologia, por exemplo.

A combinação de variáveis no primeiro e segundo níveis ilustra o problema de decisão do agente. Os agentes envolvidos no desmatamento tomam decisões sobre variáveis de escolha baseados nas próprias características, tais como as quantidades a produzir e os fatores de produção necessários, e também com base nos parâmetros exógenos de decisão, tal como preço dos produtos e custo dos insumos. Na realidade, ambos determinam o conjunto de escolhas possíveis, as quais constituem a causa imediata do desmatamento.

Finalmente, no terceiro nível, o ambiente econômico, político, cultural, demográfico e tecnológico determina as caracterís-

\section{Figura 1_ Estrutura dos diferentes níveis que afetam o desmatamento}

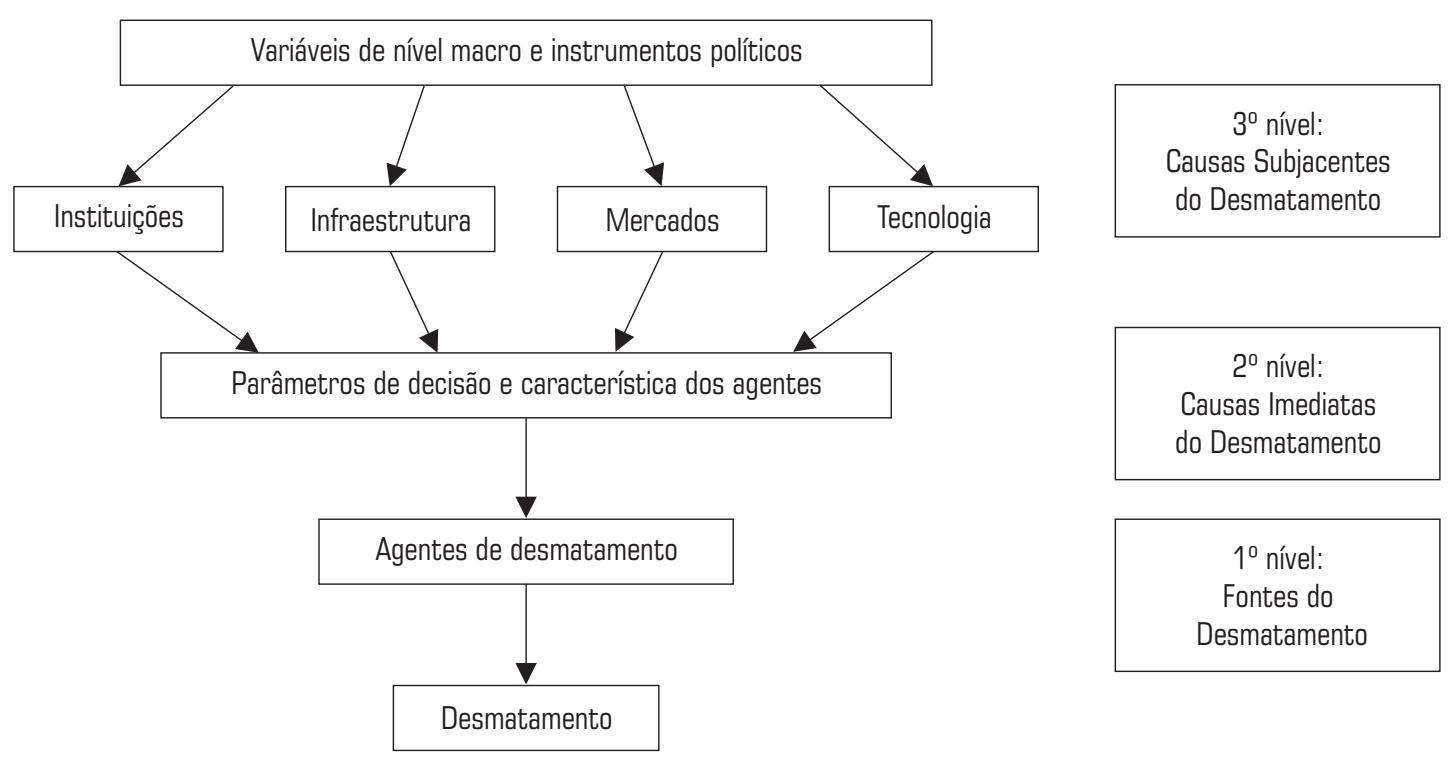

Fonte: Elaboração própria com base em Kaimowitz e Angelsen (1998). 
ticas do agente e os parâmetros de decisão, uma vez que eles estabelecem o comportamento e o funcionamento de mercados e instituições, afetam o nível tecnológico e apontam para os vetores de infraestrutura. Esses fatores podem ser pensados como as causas subjacentes do desmatamento.

Como é possível observar, as causas do desmatamento são diversas, bem como suas origens, fontes e nível de abrangência. Como apontado por Kaimowitz e Angelsen (1998), dependendo dos objetivos, os trabalhos sobre o desmatamento são de diversos tipos (analíticos, empíricos e de simulação) e abrangem, por decorrência, diversas metodologias, as quais são escolhidas de acordo com os objetivos, os tipos e a disponibilidade de dados. Os aspectos metodológicos deste trabalho, como a escolha das variáveis, sua capacidade explicativa das variáveis e os procedimentos de estimação do modelo econométrico, são descritos logo abaixo.

De acordo com os objetivos apresentados anteriormente, para analisar a relação entre os diversos tipos de gasto público e o desmatamento, o presente artigo realiza a estimação de um modelo econométrico considerando os 211 municípios do Estado do Pará. Por isso, ele se caracteriza dentro da escala regional, visto que a região de análise transcende a escala do produtor e se constitui como parte do âmbito nacional.

Desde que o desmatamento é o resultado de um processo complexo gerado por distintas razões em diferentes níveis e decorrente do fato de que não existe um modelo teórico consolidado sobre a temática do desmatamento (Scrieciu, 2003), o processo de seleção das variáveis explicativas para o modelo apoiou-se em três critérios: nos referenciais analíticos, na literatura consultada e na disponibilidade de dados (ver Quadro 1).

Em notação matemática, o modelo econométrico a ser estimado é:

$$
\begin{aligned}
\text { Desmat }_{i t}= & \alpha_{i t}+\beta_{1} P o p_{i t}+\beta_{2} C R_{i t}+\beta_{3} G A_{i t}+\beta_{4} G T_{i t}+ \\
& +\beta_{5} R b_{i t}+\beta_{6} I P T_{i t}+\beta_{7} P S_{i t}+\beta_{8} I P P_{i t}+ \\
& +\beta_{9} Y_{i t}+\beta_{10} G G A_{i t}+\beta_{11} E M_{i t}+e_{i t}
\end{aligned}
$$

Em que os subscritos $i$ e $t$ representam, respectivamente, o município analisado e o ano de observação das informações.

Dessa forma, $i=1, \ldots, 211$, e $t=$ 2002, 2003 e 2004; $\alpha$ e os $\beta$ são o conjunto de coeficientes a ser estimados.

Assim, tem-se um painel de dados considerando os 211 municípios do Estado do Pará, durante o período de 2002 a 2004, portanto, 633 observações para cada variável do modelo. 
Quadro 1_Detalhamento das variáveis utilizadas no modelo

\begin{tabular}{|c|c|c|c|c|c|}
\hline & Variável & Representação & Unidade & $\begin{array}{l}\text { Sinal esperado } \\
\text { do coeficiente }\end{array}$ & Fonte \\
\hline Variável Dependente & Desmat. & Área Desmatada & $\mathrm{km}^{2}$ & Variável de interesse & Inpe - Prodes \\
\hline \multirow{11}{*}{ Variáveis Explicativas } & Pop & População & Unidades & positivo & IBGE \\
\hline & $\mathrm{CR}$ & Crédito rural & Reais de 2000 & positivo & Banco Central(a) \\
\hline & GA & Gasto em agricultura & Reais de 2000 & positivo & STN(b) \\
\hline & GT & $\begin{array}{c}\text { Gasto no sistema } \\
\text { de transporte }\end{array}$ & Reais de 2000 & positivo & STN \\
\hline & GGA & Gasto em Gestão Ambiental & Reais de 2000 & negativo & STN \\
\hline & $\mathrm{Rb}$ & Rebanho bovino & Unidades & positivo & IBGE \\
\hline & IPT & $\begin{array}{c}\text { Índice de preço } \\
\text { da agricultura temporária }\end{array}$ & Índice de 2000 & positivo & IBGE \\
\hline & PS & Preço da soja & Reais de 2000 & positivo & IBGE \\
\hline & IPP & $\begin{array}{c}\text { Índice de preço } \\
\text { da agricultura permanente }\end{array}$ & Índice de 2000 & positivo & IBGE \\
\hline & $\mathrm{Y}$ & Renda municipal & Reais de 2000 & positivo & IPEADATA \\
\hline & EM & Extração madeireira & Metros cúbicos & positivo & IBGE \\
\hline
\end{tabular}

(a) BANCO CENTRAL DO BRASIL. Disponível em: <http://bcb.gov.br/?RELRURAL >. Acesso em: 8 ago. 2008.

(b) BRASIL. Secretaria do Tesouro Nacional. Disponível em: <http://www.stn.fazenda.gov.br/estatistica/est_estados.asp >. Acesso em: 8 ago. 2008.

Fonte: Elaboração própria.

\section{1_Capacidade explicativa das variáveis explanatórias}

A população impacta sobre o desmatamento porque ela se utiliza diretamente dos recursos materiais, in natura ou semielaborados, provenientes da floresta, co- mo uso alternativo do solo e também pela extração de recursos do subsolo.

O crédito rural fornece recursos financeiros para os produtores expandirem suas atividades. Da mesma forma, os gastos do governo em agricultura criam condi- 
ções, tanto materiais quanto institucionais, para a expansão da atividade agropecuária.

Os gastos do governo no sistema de transporte geram melhores condições de logística. Dois desdobramentos estão diretamente relacionados: o primeiro é dar condições de acesso a lugares remotos que antes estavam inacessíveis, e o segundo é contribuir para a queda em geral com o custo do transporte, tornando economicamente viável expandir a produção de certos bens para outras áreas mais distantes do mercado ou do ponto de escoamento da produção. O acesso a novos lugares, somado com a expansão de atividades econômicas, gera a ocupação de novas áreas, traduzindo no aumento do desmatamento.

Os gastos do governo em Gestão Ambiental consistem em realizações do governo federal cujo objetivo é preservar o estado natural de determinada área pertencente ao município ou sua recuperação quando algum dano ambiental estiver incidido sobre essa área.

Já as demais variáveis (rebanho bovino, índice de preço da agricultura temporária, preço da soja, índice de preço da agricultura permanente, renda municipal e extração madeireira) foram incluídas para a melhor especificação do modelo adotado. Dessa forma, é possível compreender adequadamente os efeitos dos gastos do go- verno, na medida em que as demais variáveis explicativas do desmatamento não vão constar no termo de erro do modelo.

\subsection{Procedimentos econométricos}

Com os dados disponíveis e os propósitos do artigo, a abordagem empírica pertinente é utilizar modelos econométricos que exploram as características cross-section ao longo do tempo, ou seja, o modelo de painel de dados. Uma das vantagens desse modelo é possibilitar

ao pesquisador investigar efeitos econômicos que não podem ser identificados apenas com o uso de dados em corte transversal ou apenas com o uso de séries temporais (Pindyck e Rubinfeld, 2004, p. 288).

Utilizando a notação matricial, como proposto por Greene (2003), a estrutura básica do modelo de regressão que utiliza painel de dados é:

$y_{i t}=x^{\prime}{ }_{i t} \beta+z^{\prime}{ }_{i t} \alpha+e_{i t}$

em que: $y_{i t}$ é a variável endógena referente ao município $i$ no ano $t$. Existem $k$ variáveis exógenas em $x_{i t}$, não incluindo o termo constante. A heterogeneidade, ou o também chamado efeito individual, é representada por $z^{\prime}{ }_{i} \alpha$, sendo que $z_{i}$ contém um termo constante e um conjunto de variáveis específicas de cada unidade cross-section, as quais podem ser observadas ou não. 
Existem três possibilidades de estimação dos parâmetros quando se está diante de dados em painel. O procedimento utilizado depende da observação de $z_{, i}$ e de sua correlação com a matriz de dados $x_{i t}$. O primeiro deles é o modelo Pooled (empilhamento de dados); esse modelo especifica que se $z_{i}$. contém somente um termo constante, então o método dos Mínimos Quadrados Ordinários (MQO) fornece estimativas consistentes e eficientes de $\alpha$, que é comum a todas as unidades cross-sections, e também dos demais parâmetros $(\beta)$ associados às variáveis explicativas.

Se $z_{, i}$ é não observável e correlacionado $\operatorname{com} x_{i t}$, então o estimador de $\beta$ por MQO é tendencioso e inconsistente em consequência da omissão de variável. Entretanto, o modelo $y_{i t}=x^{\prime}{ }_{i t} \beta+\alpha_{i}+e_{i t}$ contém todos os efeitos observáveis e especifica uma média condicional estimável. Esse procedimento, conhecido como efeito fixo, considera $\alpha_{i}$ como termo constante grupoespecífico no modelo de regressão. O modelo de efeito fixo pode ser estimado por meio do método dos Mínimos Quadrados Ordinários (MQO), acrescido da variável binária, o qual gera estimadores consistentes e não viesados para os parâmetros.

$\mathrm{E}$, se a heterogeneidade individual não observável pode ser pressuposta não correlacionada com as variáveis explicati- vas do modelo, então a estrutura pode ser formulada por:

$y_{i t}=x^{\prime}{ }_{i t} \beta+\left(\alpha+u_{i}\right)+e_{i}$

que é o modelo de efeito aleatório. A diferença é a presença do componente $u_{i}$, que é o distúrbio aleatório, que caracteriza o i-ésimo município e que é constante ao longo do tempo. Existem $k$ parâmetros incluindo o termo constante e, neste caso, o termo constante é a média das heterogeneidades não observáveis.

Dada a presença da matriz de variância-covariância dos erros, está-se diante do modelo heterocedástico, assim a estimação dos parâmetros é realizada pelo método dos Mínimos Quadrados Generalizados (MQG).

O Quadro 2 resume os testes apropriados e as consequentes decisões quando se utiliza o modelo de painel de dados. Se o teste F de Chow for significativo, o modelo de efeito fixo deve ser utilizado; caso contrário, o modelo Pooled deve ser o aplicado. Se o teste de Breusch e Pagan for significativo, utiliza-se o modelo de efeito aleatório; caso contrário, o modelo Pooled. E, quando o teste de Hausman for significativo, o modelo de efeito aleatório é preferível ao modelo de efeito fixo, e, quando esse teste for não significativo, é preferível o modelo de efeito fixo. 
Quadro 2_Regra de decisão para a escolha do modelo econométrico adotado

\begin{tabular}{|c|c|c|}
\hline \multirow{2}{*}{ Tipo de Teste } & \multicolumn{2}{|c|}{ Resultado do Teste } \\
\hline & Significativo & Não Significativo \\
\hline Teste F de Chow & $\begin{array}{c}\text { É preferível o modelo } \\
\text { de efeito fixo }\end{array}$ & É preferível o modelo Pooled \\
\hline $\begin{array}{l}\text { Teste de Breusch e Pagan } \\
\text { (Multiplicador de Lagrange) }\end{array}$ & $\begin{array}{l}\text { É preferível o modelo } \\
\text { de efeito aleatório }\end{array}$ & É preferível o modelo Pooled \\
\hline Teste de Hausman & $\begin{array}{c}\text { É preferível o modelo } \\
\text { de efeito aleatório }\end{array}$ & $\begin{array}{c}\text { É preferível o modelo } \\
\text { de efeito fixo }\end{array}$ \\
\hline
\end{tabular}

Fonte: Elaboração própria.

\section{4_Resultados}

Entre os Estados que compõem a Amazônia Legal, é o Pará o que apresenta, nos últimos anos, as maiores áreas desmatadas. A Tabela 1 mostra a área desmatada entre 2002 e 2004, no Estado do Pará. Entre 2002 e 2004, a velocidade do desmatamento aumentou, saltando de $8636,4 \mathrm{~km}^{2}$ por ano, em 2002, para $9648,5 \mathrm{~km}^{2}$ por ano, em 2003, e 1043,9km² por ano, em 2004. Isso significa um aumento na velocidade de $11,7 \%$, em 2003, e 7,9\%, em 2004 .

Em relação ao desmatamento acumulado, o Estado do Pará tinha, em 2002, $172.203,5 \mathrm{~km}^{2}$ desmatados; em 2003, essa área passou para $181.852 \mathrm{~km}^{2}$, e em 2004 para $192.265,9 \mathrm{~km}^{2}$. Em valores percentuais, o desmatamento acumulado cresceu 5,6\%, em 2003, e 5,7\%, em 2004. Nesse último ano, a área desmatada no Pará representou $15,4 \%$ do total do seu território.

Dos volumes financeiros controlados pelo governo, o crédito foi o mais expressivo no Estado do Pará, entre 2002 e 2004. Como pode ser visualizado na Tabela 2, entre 2002 e 2004, o valor concedido de crédito aumentou $69,9 \%$, em 2003, e 31,3\%, em 2004, totalizando no período um aumento de $123,2 \%$, saltando de $\mathrm{R} \$ 2,43$ bilhões, em 2002, para R\$5,43, em 2004.

Tahela 1_Área desmatada e desmatamento acumulado no Estado do Pará (km²)

\begin{tabular}{|c|c|c|c|}
\hline & 2002 & 2003 & 2004 \\
\hline Área Desmatada Anualmente & $8.636,4$ & $9.648,5$ & $10.413,9$ \\
\hline Desmatamento Acumulado & $172.203,5$ & 181.852 & $192.265,9$ \\
\hline
\end{tabular}

Fonte: INSTITUTO NACIONAL DE PESQUISAS ESPACIAIS (INPE). Prodes Digital. São José dos Campos. 2008.

Disponível em: <http://www.obt.inpe.br/ prodesdigital/metodologia.html>. Acesso em: 10 out. 2008. 
Tabela 2 Valor concedido em crédito rural e em gastos do governo por função (R\$ de 2002)

\begin{tabular}{|c|c|c|c|}
\hline & 2002 & 2003 & 2004 \\
\hline Crédito Rural & 2.432 .367 .954 & 4.133 .527 .708 & 5.430 .078 .048 \\
\hline Agricultura & 151.235 .487 & $116.167 .230,5$ & $89.071 .063,2$ \\
\hline Transporte & $460.507 .322,6$ & $338.560 .894,1$ & $324.407 .263,7$ \\
\hline Gestão Ambiental & $49.892 .623,51$ & $41.169 .500,71$ & $49.011 .832,14$ \\
\hline
\end{tabular}

Os gastos do governo em agricultura diminuíram ao longo do período analisado no Estado do Pará. Em 2002, o valor gasto nessa função foi de $\mathrm{R} \$ 151,2 \mathrm{mi}$ lhões; em 2003, foi de R\$116,1 milhões, e, em 2004, de $\mathrm{R} \$ 89$ milhões. Isso representa uma redução de 41,1\%, entre 2002 e 2004.

Os gastos do governo com a função transporte foi o mais alto entre os demais no período analisado. No entanto, como se pode perceber por meio de Tabela 2 , os valores gastos tiveram uma queda progressiva nos anos de 2003 e 2004, comparados com o ano anterior. Essa queda não foi tão expressiva como no caso dos gastos em agricultura, mas foi de 23,1\%, em 2003, e $23,3 \%$, em 2004 , totalizando no período uma redução de $29,5 \%$.

Os gastos em gestão ambiental são, em termos financeiros, os menos expressivos. Embora o governo tenha vários programas relacionados ao meio ambiente, a análise de seus gastos mostra que suas ações ainda carecem de maiores recursos.

Em 2002, o valor gasto com essa função no Estado do Pará foi de R \$ 49,8 milhões; em 2003, o valor caiu para $\mathrm{R} \$ 41,1$ milhões, o que representa uma queda de 17,4\%; e, em 2004, o valor gasto foi de $\mathrm{R} \$ 49$ milhões. Em relação ao ano de 2003, os gastos de 2004 representam um aumento de 19\%, mas, em comparação com 2002, uma queda de $1,7 \%$.

A queda dos valores gastos pode estar relacionada com a transição do governo federal. Como se bem sabe, o período de análise desta pesquisa foi de transição de governo, o que pode ocasionar em uma redefinição dos gastos, uma vez que tais gastos são de natureza eminentemente política, e que qualquer decisão de gastos pode se alterar com as mudanças de governo.

A Tabela 3, a seguir, mostra as estatísticas descritivas das variáveis incluídas no modelo econométrico. Entre 2002 e 2004, a média de desmatamento por município foi de aproximadamente $50 \mathrm{~km}^{2}$ anuais. Como pode ser observado, o desvio padrão do desmatamento ao longo do tempo (within) é menor que o desvio padrão entre os municípios (between). Isso mostra que o desmatamento no Estado do Pará é influenciado pelas características individuais de cada município, que, como salientado, pode ser observada ou não. 
Tabela 3_Estatística descritiva das variáveis analisadas no modelo econométrico

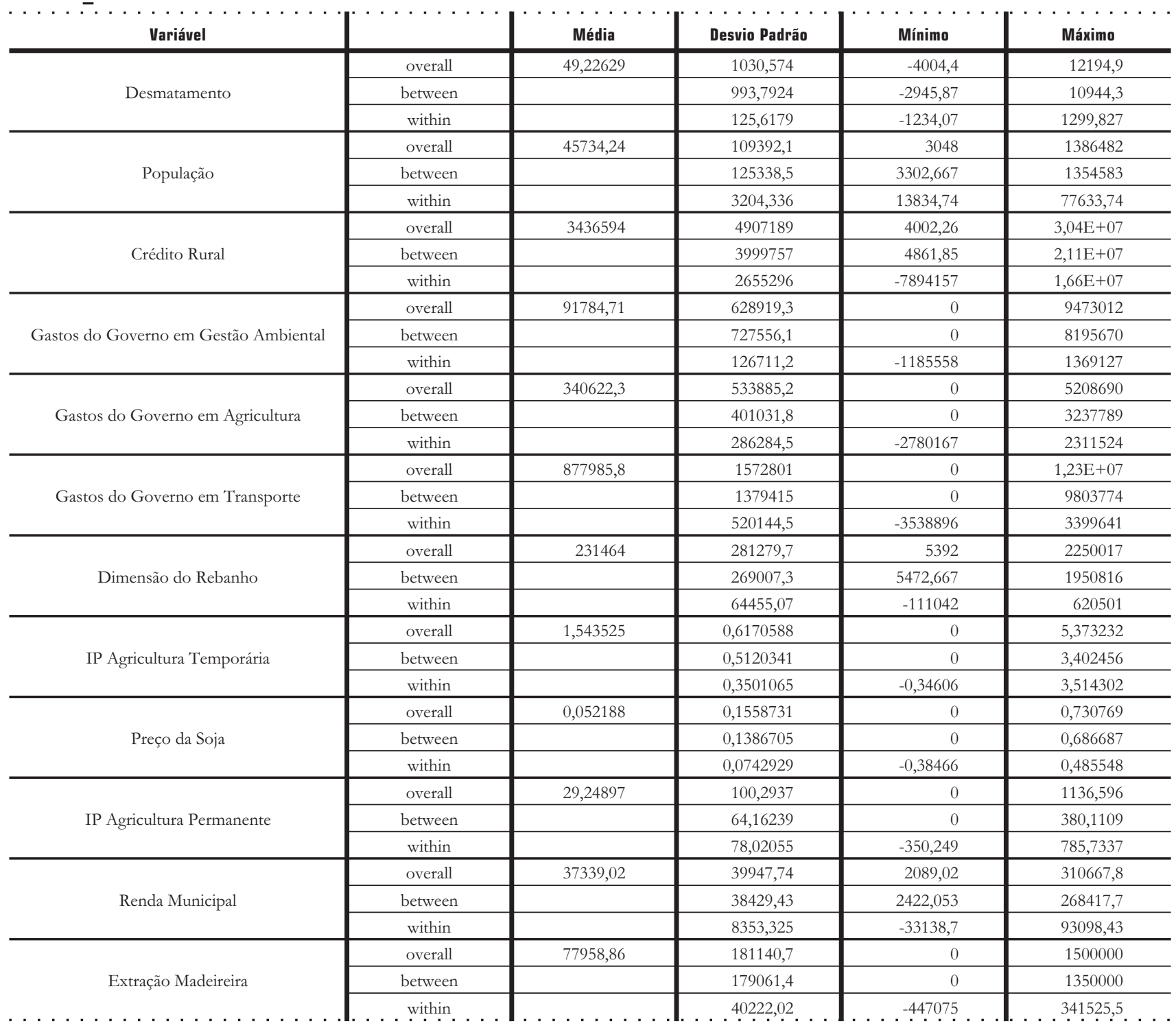

Fonte: Elaboração própria. 
Em relação às variáveis de interesse desta análise, a média do crédito rural foi de $\mathrm{R} \$ 3.436 .594,00$ por município, por ano; a média dos gastos em gestão ambiental foi de $\mathrm{R} \$ 91.784,71$, anualmente, por município; a média dos gastos anuais em agricultura foi de $\mathrm{R} \$ 340.622,30$ por município; e a média anual por município dos gastos no sistema de transporte foi de $\mathrm{R} \$ 877.985,80$. Da mesma forma ocorrida com o desmatamento, o desvio padrão das variáveis citadas foi maior entre os municípios do que ao longo do tempo, indicando uma grande diferença entre os municípios do que no decorrer do tempo para o mesmo município.

Diante das opções econométricas existentes, é fundamental verificar qual dos modelos econométricos os testes apontam como o de maior eficiência. De acordo com os testes estatísticos realizados (ver parte inferior da Tabela 4), o teste F de Chow, por ser significativo, deixa claro que o modelo de efeito fixo é preferível ao modelo Pooled. Da mesma forma, o teste de Breusch e Pagan, que também é significativo, mostra que o modelo de efeito aleatório também é preferível ao modelo Pooled. Já o teste de Hausman, não significativo, mostra que o modelo de efeito fixo é preferível ao modelo de efeito aleatório. Assim, a análise a seguir se concentra nas estimativas geradas pelo modelo de efeito fixo. Além disso, como também pode ser observado na parte final da tabela, o $\mathrm{R}^{2}$ ajustado é relativamente alto, tornando boa a capacidade explicativa e de previsão do modelo adotado.

De acordo com a literatura específica, que aponta para os fatores causadores do desmatamento, o modelo estimado para o Pará corrobora para alguns fatores enquanto descarta a importância de outros para explicar o desmatamento nesse Estado. Vale ressaltar que a escolha das variáveis esteve embasada na literatura, e não necessariamente a totalidade delas se revela pertinente para explicar o desmatamento em alguma região. Isso se deve ao fato de que os fatores causadores do desmatamento são desiguais espacial e temporalmente. Além disso, mesmo presentes, a intensidade dos fatores também se difere entre as regiões ou os municípios analisados.

Como a maioria dos trabalhos empíricos, a variável população se mostrou estatisticamente significativa para explicar o desmatamento no Pará. No entanto, e como alertado pela literatura sobre o tema, convém ressaltar que não é simplesmente a presença da população ou seu crescimento que impactam positivamente sobre o desmatamento, mas sim as atividades econômicas que ela desenvolve. 
Tabela 4_ Resultados do modelo de regressão estimado para o Pará

\begin{tabular}{|c|c|c|c|}
\hline \multirow{2}{*}{ Variáveis Explicativas } & \multicolumn{3}{|c|}{ Modelo de Regressão } \\
\hline & Pooled & Efeito Fixo & Efeito Aleatório \\
\hline População & $\begin{array}{c}-0,00234 \\
(-1,56) \\
\end{array}$ & $\begin{array}{c}0,0099949^{(b)} \\
(2,49)\end{array}$ & $\begin{array}{c}0,002976 \\
(1,32)\end{array}$ \\
\hline Crédito Rural & $\begin{array}{c}9,36 \mathrm{E}-05^{(\mathrm{a})} \\
(4,12)\end{array}$ & $\begin{array}{c}1,85 \mathrm{E}-05^{(\mathrm{a})} \\
(4,21)\end{array}$ & $\begin{array}{c}2,09 \mathrm{E}-05^{(\mathrm{a})} \\
(3,93)\end{array}$ \\
\hline $\begin{array}{c}\text { Gastos em Gestão } \\
\text { Ambiental }\end{array}$ & $\begin{array}{c}0,001106^{(a)} \\
(2,64)\end{array}$ & $\begin{array}{c}-0,00038^{(a)} \\
(-3,05)\end{array}$ & $\begin{array}{c}-0,00043^{(a)} \\
(-2,69)\end{array}$ \\
\hline Gastos em Agricultura & $\begin{array}{c}-0,00017 \\
(-0,95)\end{array}$ & $\begin{array}{c}-1,3 \mathrm{E}-05 \\
(-0,42)\end{array}$ & $\begin{array}{c}4,48 \mathrm{E}-06 \\
(0,11)\end{array}$ \\
\hline Gastos em Transporte & $\begin{array}{l}-5 \mathrm{E}-05 \\
(-0,81)\end{array}$ & $\begin{array}{c}9,26 \mathrm{E}-05^{(\mathrm{a})} \\
(4,73)\end{array}$ & $\begin{array}{c}7,97 \mathrm{E}-05^{(\mathrm{a})} \\
(3,16)\end{array}$ \\
\hline Dimensão do Rebanho & $\begin{array}{c}0,002355^{(\mathrm{a})} \\
(3,92)\end{array}$ & $\begin{array}{c}0,001792^{(a)} \\
(6,85)\end{array}$ & $\begin{array}{c}0,002104^{(a)} \\
(7,12)\end{array}$ \\
\hline $\begin{array}{l}\text { Índice de Preços da } \\
\text { Agricultura Temporária }\end{array}$ & $\begin{array}{c}213,5074 \\
(1,51)\end{array}$ & $\begin{array}{c}33,41625 \\
(1,02)\end{array}$ & $\begin{array}{c}41,49133 \\
(0,96)\end{array}$ \\
\hline Preço da Soja & $\begin{array}{c}-1173(\mathrm{~b}) \\
(-2,11)\end{array}$ & $\begin{array}{c}-35,1868 \\
(-0,26)\end{array}$ & $\begin{array}{c}33,60858 \\
(0,19)\end{array}$ \\
\hline $\begin{array}{l}\text { IP da Agricultura } \\
\text { Permanente }\end{array}$ & $\begin{array}{c}-0,9539 \\
(-1,02)\end{array}$ & $\begin{array}{c}0,195767 \\
(1,15)\end{array}$ & $\begin{array}{c}0,21123 \\
(0,93)\end{array}$ \\
\hline Renda Municipal & $\begin{array}{c}0,020141^{(a)} \\
(5,97)\end{array}$ & $\begin{array}{c}-0,00706^{(a)} \\
(-6,05) \\
\end{array}$ & $\begin{array}{c}-0,00313^{(b)} \\
(-2,14) \\
\end{array}$ \\
\hline Extração Madeireira & $\begin{array}{c}0,000179 \\
(0,31) \\
\end{array}$ & $\begin{array}{c}0,000263 \\
(1,19) \\
\end{array}$ & $\begin{array}{c}0,000333 \\
(1,2) \\
\end{array}$ \\
\hline Constante & $\begin{array}{c}-157,063 \\
(-0,61)\end{array}$ & $\begin{array}{c}1048,578^{(a)} \\
(4,87)\end{array}$ & $\begin{array}{c}958,4169^{(a)} \\
(5,08)\end{array}$ \\
\hline $\mathrm{R} 2$ ajustado & 0,6922 & 0,7162 & 0,6454 \\
\hline Observações & 633 & 633 & 633 \\
\hline Teste F (Chow) & & $147,22^{(a)}$ & \\
\hline Teste de Breush e Pagan & & & $71,79^{(a)}$ \\
\hline Teste de Hausman & & & 0,52 \\
\hline
\end{tabular}

(a) denota significância a $1 \%$

(b) denota significância a 5\%

(c) denota significância a $10 \%$

Fonte: Elaboração própria.

Nota: Entre parênteses, a estatística $t$ de Student. 
Sobre tais atividades econômicas, não existe uma teoria ou mesmo trabalhos empíricos que mostram a relação entre o desmatamento e o setor terciário da economia. Sobre o setor secundário, dependendo da natureza da produção industrial, é possível estabelecer alguma relação entre o desmatamento e esse setor; no entanto, tal relação se caracteriza como uma exceção, e não como uma regra. Tendo isso em vista, a análise se concentra nas atividades econômicas que necessitam amplamente do solo para sua existência. Nesse sentido, a pecuária, aqui mensurada pela dimensão do rebanho bovino, é um fator importante para explicar o desmatamento no Estado do Pará. Em 2006, a área destinada à pastagem foi de $131.678 \mathrm{~km}^{2}, 76,6 \%$ superior a 1995. Em 2006, o Pará tinha a segunda maior área destinada à pastagem, atrás apenas do Estado do Mato Grosso.

Em relação à agricultura, nenhum índice de preços se mostrou estatisticamente significativo, quer seja da agricultura temporária, quer seja da soja, quer seja da agricultura permanente. A área destinada à agricultura no Pará foi de $32.143 \mathrm{~km}^{2}$, o que representa menos da metade da área cultivada no Mato Grosso, que é o Estado de maio produção agrícola da Amazônia Legal. Além disso, soja não é uma cultura importante no Pará. Em 2005, a área cultiva- da foi de 68.410 hectares, muito abaixo, por exemplo, do Mato Grosso, que, no mesmo ano, cultivou mais de 6 milhões de hectares com soja. Assim, não é de se esperar que o preço da soja nesse Estado tenha impacto expressivo sobre o desmatamento.

A extração madeireira também não se mostrou estatisticamente significativa. Sobre isso cabe a ressalva de que os dados utilizados são oficiais, com base no IBGE, e eles podem não captar adequadamente a verdadeira extração madeireira, dado que uma importante parcela dessa atividade é ilegal. Assim, os dados oficiais podem não trazer significância estatística ao modelo.

A variável renda municipal é estatisticamente significativa; no entanto, apresentou sinal contrário ao esperado. $\mathrm{Na}$ literatura, existem trabalhos que testam o impacto da renda em alguma variável ambiental por meio da curva de Kuznets Ambiental, a qual tem forma de $\mathrm{U}$ invertido, e mostra que, com o aumento da renda até determinado nível, ocorre um aumento do dano ambiental, e, a partir desse determinado valor, o aumento da renda gera menor dano ambiental. Pode ser que a renda cause impacto negativo, contrariando o presente modelo, graças ao fenômeno da curva de Kuznets Ambiental na sua fase decrescente.

A variável crédito rural é estatisticamente expressiva, e o seu sinal está de acor- 
do com as pressuposições do modelo. Isso mostra que, conforme o governo disponibiliza recursos para financiar a atividade $\mathrm{da}$ agropecuária, ela se expande para novas áreas, elevando o desmatamento. O crédito rural significa o acesso do produtor aos meios necessários para o exercício da atividade agropecuária. É importante ressaltar que o crédito rural é, em última instância, uma decisão governamental e que pode estar dentro de uma política de desenvolvimento regional. Dessa forma, indiretamente, o governo financia o desmatamento em determinada região por meio do crédito rural.

A variável gastos em transportes também se mostrou estatisticamente significativa. Conforme aumentam os gastos nessa função, maior é a área desmatada. Isso, como já salientado, torna acessíveis áreas que até então não eram. Além disso, melhorando o sistema de transporte, por meio de sua ampliação ou remodelação, os custos de transporte diminuem, o que estimula ou viabiliza a implantação de atividades que necessitem do solo e que concorram com a floresta. Muitos trabalhos afirmam que são as redes de estradas não oficiais, aquelas abertas principalmente pelos madeireiros, que causam o desmatamento. No entanto, as estradas não oficiais estão conectadas às oficiais; assim, a expansão das oficiais permite ao longo do seu eixo a ramificação das não oficiais.
Em relação aos gastos em agricultura, seu sinal contraria o esperado no modelo; no entanto, ela não é estatisticamente significativa. Isso pode estar relacionado à multiplicidade de áreas que essa função estabelece, e que, não necessariamente, implica o desmatamento.

A variável gastos em gestão ambiental é estatisticamente significante, e seu sinal está de acordo com os pressupostos do modelo. Portanto, maiores gastos nessa função reduzem a área desmatada.

Com os coeficientes estimados, foram calculadas as elasticidades do desmatamento em relação a cada uma das variáveis incluídas no modelo (ver Tabela 5). A elasticidade é uma forma de mensurar a sensibilidade do desmatamento em relação aos fatores causadores.

Sem nenhuma dúvida, o impacto da população é extremamente significativo, já que o aumento em $1 \%$ impacta no aumento de $0,34 \%$ na área desmatada no Pará. Da mesma forma é a dimensão do rebanho bovino, à medida que o rebanho aumenta em $1 \%$, o desmatamento aumenta $0,29 \%$.

Mas, em relação às políticas públicas, medidas pelos seus gastos e pelo crédito rural, o de maior impacto são os gastos em transporte. 
Tabela 5_Elasticidades dos fatores causadores do desmatamento

\begin{tabular}{|c|c|}
\hline Variável & Elasticidade \\
\hline População & 0,34654607 \\
\hline Crédito Rural & 0,044915422 \\
\hline Gastos em Gestão Ambiental & $-0,029339876$ \\
\hline Gastos em Agricultura & $\mathrm{nse} / \mathrm{scm}$ \\
\hline Gastos em Transporte & 0,059435556 \\
\hline Dimensão do Rebanho & 0,294199 \\
\hline Índice de Preços da Agricultura Temporária & 0,037122857 \\
\hline Preço da Soja & $\mathrm{nse} / \mathrm{scm}$ \\
\hline IP da Agricultura Permanente & 0,003967124 \\
\hline Renda Municipal & $\mathrm{scm}$ \\
\hline Extração Madeireira & 0,014805394 \\
\hline
\end{tabular}

nse $=$ não significativo estatisticamente

$\mathrm{scm}=$ sinal contraria o modelo

Fonte: Elaboração própria

Como se pode observar na Tabela 5 , o aumento de $1 \%$ nessa função representa o aumento de $0,059 \%$ no desmatamento. Já o impacto do crédito rural é menor, aumento de 0,044\% na área desmatada para aumento de $1 \%$ no crédito. $\mathrm{E}$, em relação aos gastos em gestão ambiental, o aumento de $1 \%$ nessa função reduz o desmatamento em $0,029 \%$.

\section{5_Considerações finais}

Compreender as razões ou os fatores que geram o desmatamento no Estado do Pará é de importância fundamental, visto que é nele onde se encontram os maiores níveis de desmatamento na região da Amazônia Legal. A literatura sobre o desmatamento aponta uma série de fatores; no entanto, nem todos são válidos para explicar esse fenômeno em uma determinada região.

Dos fatores considerados no modelo para o Estado do Pará, são pertinentes a população, a dimensão do rebanho, o crédito rural, os gastos em transporte e os gastos em Gestão Ambiental. Dos cinco fatores, três deles têm influência direta das políticas públicas, e essa relação merece atenção maior. 
Os resultados mostram que os fatores influenciados direta ou indiretamente pelo governo, exercidos por meio de políticas públicas, têm importante impacto sobre o desmatamento. Em especial, vale ressaltar que o crédito rural e os gastos em transportes causam impacto positivo; já os gastos em gestão ambiental impactam negativamente sobre o desmatamento. Os gastos em agricultura, por sua vez, não se mostraram importantes para explicar o desmatamento no Pará. Como os gastos constituem dispêndios do governo, e sendo que eles impactam de forma diferenciada sobre o desmatamento, pode-se questionar se os gastos estão sendo coordenados adequadamente, pois, como foi comprovado de forma empírica, o governo estabelece políticas que se podem anular.

Mesmo diante de circunstâncias nas quais são necessárias ações (políticas) opostas, o governo pode não estar utilizando os gastos em Gestão Ambiental para controlar adequadamente os efeitos gerados pelos gastos em transporte ou pelos recursos destinados ao crédito rural.

Esse comportamento também pode indicar que o governo tem preferência por políticas que não tenham compromisso claro com o meio ambiente, e, em particular, por políticas que visam derrubar a floresta e utilizar o solo de forma alternati- va. Ou seja, no entendimento do governo, os benefícios gerados na área desmatada são superiores aos custos da perda da floresta. 


\section{Referências bibliográficas}

ANDERSEN, L. E.; REIS, E. J. Deforestation, development, and government policy in the Brazilian Amazon: an econometric analysis. Brasília: IPEA, 1997. (Texto para Discussão, 513).

ARIMA, E. Y.; WALKER, R. T.; PERZ, S. G.; CALDAS, M.

Loggers and forest fragmentation: behavioral models of road building in the Amazon basin. Annals of American Geographers. Washington, v. 95, n. 3, p. 525-541, 2005.

BARRETO, P.; SOUZA JÚNIOR, C.; NOGUERÓN, R.; ANDERSON, A.; SALOMÃO,

R. Pressão bumana da floresta amazônica brasileira. Belém: Imazon, 2005

BRANDÃO, A. S. P.; REZENDE, G. C.; MARQUES, R. W. C. Agricultural growth in the period 1999-2004, outburst in soybeans area and environmental impacts in Brazil. Brasília: IPEA, 2005. (Texto para Discussão, 1062).

BRASIL. Ministério da Fazenda. Secretaria do Tesouro Nacional. Relatório de Atividades 1998 a 2007. Brasília, 2007. 115p.
CROPPER, M.; GRIFFITHS, C.; MANI, M. Roads, population pressures and deforestation in Thailand, 1976-1989. Washington: The World Bank, 1996.

CULLAS, R.; DUTTA, D. The underlying causes of deforestation and environmental Kuznets curve: a cross-country analysis. In: Econometric Society of Australia Meeting (ESAM). Brisbane: ESAM, 2002.

FEARNSIDE, P. M.; GRACA, P. M. L. A. BR-319: Brazil's Manaus-Porto Velho highway and the potential impact of linking the arc of deforestation to central

Amazonia. Environmental

Management, v. 38, n. 2, p. 705-716, 2006.

FERRAZ, C. M. Measuring the causes of deforestation, agriculture, land conversion and cattle ranching growth: evidence from the Amazon. Brasília: IPEA, 2000. 122p. Disponível em:

$<$ http://www.econ.fea.usp.br/se minarios/2006_2/igliori_22_09_2 006.pdf $>$. Acesso em:

20 fev. 2007.

FERRAZ, C. Explaining agriculture expansion and deforestation: evidence from the Brazilian Amazon 1980/98. Brasília: IPEA, 2001. (Texto para Discussão, 828).
GASQUES, J. G. Gastos públicos na agricultura. Brasília: IPEA, 2001. (Texto para Discussão, 782).

GREENE, W. Econometric analysis. New York: Prentice Hall, 2003

HOGAN, D. J. Demographic dynamics and environmental change in Brazil. Ambiente e Sociedade, v. 4, n. 9, p. 43-73, 2001.

INSTITUTO BRASILEIRO DE GEOGRAFIA E ESTATÍSTICA (IBGE). Indicadores de

desenvolvimento sustentável - Brasil. Rio de Janeiro, 2004.

INSTITUTO NACIONAL DE PESQUISAS ESPACIAIS (INPE). Monitoramento da floresta amazônica brasileira por satélite:

Projeto Prodes. São José dos Campos:INPE, 1979. Disponível em < http://obt.inpe.br/prodes / index.html >. Acesso em: $15 \mathrm{de}$ set. 2008.

INSTITUTO NACIONAL DE PESQUISAS ESPACIAIS (INPE). Prodes Digital. São José dos Campos. 2008. Disponível em: <http://www.obt.inpe.br/ prodesdigital/metodologia.html>. Acesso em: 10 out. 2008

KAIMOWITZ, D.; ANGELSEN, A. Econometric models of tropical deforestation: a review. Jakarta:

Center for International Forestry Research, 1998.
LAURANCE, W. F. ; ALBERNAZ, A. K. M.; FEARNSIDE, P. M.; VASCONCELOS, H. L.; FERREIRA, L. V. Deforestation in Amazonia, n. 304, p. 1109-1111, 2004

MARGULIS, S. Causas do desmatamento da Amazônia brasileira. Brasília: Banco Mundial, 2003.

PERZ, S. G.; ARAMBURÚ, C.; BREMNER, J. Population, land use and deforestation in the pan Amazon basin: a comparison of Brazil, Bolivia, Colombia, Ecuador, Peru and Venezuela. Environment, Development and Sustainability, v. 7, n. 1 , p. 23-49, 2005 .

PFAFF, A. S. P. What drive. deforestation in the brazilian Amazon? MIT Joint Program on the Science and Policy of Global Change. Cambridge, 1996. 32p. Disponível em: <http://web.mit.edu/ globalchange/www/rpt16.html> Acesso em: 15 maio 2007.

PFAFF, A. S. P. What drives deforestation in the Brazilian Amazon? Evidence from satellite and socioeconomic data. Journal of Environmental Economics and Management, v. 37, n. 1, p. 26-43, 1999 . 
PFAFF, A. S. P. et al. Road investments, spatial spillovers, and deforestation in the Brazilian Amazon. Journal of Regional Science, v. 47, n. 1, p. 109-123, 2007.

PIANCASTELLI, M.; PEREIRA, F. Gasto público federal: análise da despesa não-financeira. IPEA, 1996. (Texto para

Discussão, 431)

PINDYCK, R.; RUBINFELD, D Econometria: modelos e previsões. Rio de Janeiro: Elsevier, 2004.

SCRIECIU, S. Economic causes of tropical deforestation: a global empirical application. Manchester: Institute for Development Policy and Management, University of Manchester, 2003. (Working Paper, 4/2003).

SOARES FILHO, B. S NEPSTAD, D. C.; CURRAN, L. Cenários de desmatamento para a Amazônia. Estudos Avançados, v. 19 , n. 54, p. 137-152, 2005.

TANAKA, S.; NISHII, R. A model of deforestation by human population interactions.

Environmental and Ecological Statistics, v. 4, n. 1, p. 83-91, 1997.

WEINHOLD, D.; REIS, E. J.

Model evaluation and causality testing in short panels: the case of infrastructure provision and population growth in the Brazilian Amazon. Journal of Regional Science, v. 41 , n. 4 , p. $639-658,1999$.

WEINHOLD, D.; REIS, E. J.

Land use and transportation costs in the Brazilian Amazon. Brasília: IPEA, 2003.
YOUNG, C. E. F.;

RONCISVALLE, C. A.

Expenditures, investment and financing for sustainable development in Bravil. Santiago: CEPAL, 2002.

YOUNG, C. E. F. Mecanismos de financiamento para a conservação da biodiversidade no Brasil. Megadiversidade (Belo Horizonte), Belo Horizonte, v. 1, n. 1, p. 208-214, 2005.

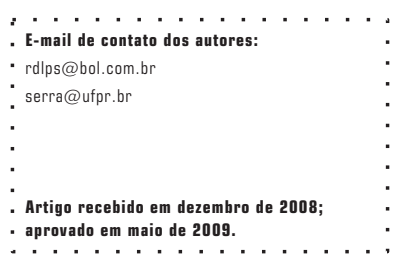

